gain enough information to enable him to collect and prepare his samples properly.

The space allocated to the various techniques varies widely, and by no means in direct proportion to their relative importance to archaeology; archaeomagnetic dating ( $60 \mathrm{pp})$ is the longest chapter, and fission track (5 pp) the shortest, with carbon-14 (48 pp) running third. Undoubtedly the differences in lengths of chapters partly reflect the extent to which the various authors have considered it necessary to discuss the technical details of their subjects, and one finds here some examples of the way in which the specialist's enthusiasm for his subject can lead him into dealing with some aspects of it in more than necessary detail. For example, the chapter on carbon-14 dating achieves a good balance between brevity and detail in describing the basis of the method, samples and sampling, interpretation of results, and radiocarbon age discrepancies, but deals with laboratory techniques and particularly that of proportional gas counting in what may seem to be unnecessary detail to the archaeologist. Technical detail also tends to obscure the section on archaeomagnetic dating from the layman's point of view, although this is admittedly a very complex subject and one appreciates the author's difficulties. In contrast one can agree that the wealth of detail in the section on obsidian dating is fully justified because this is a technique which by virtue of its low cost and relative simplicity should be within the technical competence of a small archaeological unit to set up and operate, and the chapter provides enough practical detail to make this possible.

Finally, in commenting on a book aimed at enabling the archaeologist to collect and prepare his samples properly, one must make the point that some chapters could have devoted more space to the practical aspects of sampling, or alternatively specifically warned the archaeologist against attempting it in those cases where, as in archaeomagnetic dating, the technique is highly specialized.

HAROLD BarKer

\section{Sociology of Science}

The Social Process of Innovation. By M. J. Mulkay. Pp. 64. (Macmillan: London and Basingstoke, April 1972.) $60 \mathrm{p}$.

IN this well-constructed essay, the author addresses himself primarily to the question: what sorts of scientists are the most likely to produce innovations? For this, he distinguishes between "migration" to nascent specialities and "radical innovation" that challenges existing paradigms. His description of the social process of control of research makes effective use of the concepts of "cognitive and technical norms" and also the (unstable) "research network" which enforces these on workers in each problem area. Partly by a relatively formal argument using these concepts, and partly by commonsense argument at crucial points, he arrives at a tentative conclusion: high-status men will tend to migrate, and young men to innovate radically.

Always maintaining an admirable clarity concerning his assumptions and methods, the author articulates a model of Homo scientificus. $\mathrm{He}$ is a direct descendant of Homo economicus, an entrepreneur operating on a market whose currency is prestige, and as always concerned only to get the highest price for the product of his labours. The author explicitly defends this model: "It is sometimes argued that the scientist's main reward is neither money nor recognition but rather the pleasure derived from completing a successful piece of research. However, this argument is inconsistent with the regular occurrence of priority disputes and the prevalence of anxiety over anticipation."

In accordance with this model, the psychology of the young scientist prone to radical innovation is simply that of a gambler with little to lose and much to gain. An important part of his motivation is his ignorance that he is playing with a stacked deck: "Furthermore, it seems probable that young scientists will believe more firmly than their elders in the myth of scientific impartiality. If this is so, they will be less likely to conceive that revolutionary contributions might be rejected." The author's chosen case study of innovation is the work of Pasteur on fermentation; and so he apparently believes that the great scientists of the past, who endured hardships of many sorts during their struggles for acceptance of their ideas, were all silly little opportunists who struck it lucky.

It is to be regretted that the author's useful bibliography did not include N. Storer, The Social System of Science (1966), which in spite of its naiveté is valuable as the prime source of the "exchange" model of scientific activity: Two more recent studies indicate problems that could well be worth considering in connexion with such models of Homo scientificus. I would be interested to see if the maintenance of qualitycontrol in science can be explained on such Hobbesian assumptions. And to this model of scientific activity, even more than to Kuhn's, there can be applied the Feyerabend paradox: is there anything in this analysis that does not apply equally well to gangsterism; and if not, why not?

J. R. RAVETZ

\section{Simple Liquids}

Physical Chemistry: An Advanced Treatise. Vol. 8. Liquid State. Vol. 8A, Pp. xix +1-412+14; Vol. 8B, Pp. xix+ 413-892. Edited by D. Henderson. (Academic: New York and London, December 1971.) Vol. 8A: \$23; £10.75. Vol. 8B: \$25; £11.65.

THIs treatise on the theory of molecularly simple liquids has fifteen authors, most of whom have concentrated on the developments of the last five years. Some of their material is in other books but there is here much which can be found elsewhere only in research and review papers.

Scott opens with a summary of our knowledge of intermolecular potentials; Chen and Baxter in separate but overlapping chapters discuss the determination of the structure of a liquid and its representation in terms of the distribution functions; Ree describes the computer simulation of model systems; Jhon and Eyring return to the latter's "significant structures"; and Henderson and Barker bring part A to a close with a welcome account of the perturbation theories with which they have enriched the armoury of equilibrium statistical mechanics. In part B, Henderson and Leonard apply these and other theories to liquid mixtures; ter Haar disposes of liquid helium in twenty-five pages; Berne gives us nearly two hundred on time-dependent properties, a valuable chapter which could usefully have been developed into a book in its own right; and Stephenson, Stanley, Paul and Milosevic close with two chapters on the equilibrium and dynamic properties of fluids at their critical points.

The editor has brought together some first-class players who have performed admirably. He has not, however, welded them into a team, for there is too much repetition and too little evidence that any author knew what the others were saying, except in the two chapters written by the editor himself. Thus one example of this lack of cooperation is that the important function usually written $h(r)$ is called the total, the net and the indirect correlation function in different chapters. The indexing inevitably suffers where there are such discrepancies. No doubt the editor, like others who have undertaken similar tasks, was only too glad to receive the final contribution not too many years behind the original schedule to want to spend more time correlating the material. Certainly the rich meal he has assembled would have been spoilt by keeping. The penalty of concentrating on recent developments is that this book will lose its usefulness more quickly than might be expected from a treatise. It is really a group of timely monographs.

J. S. ROWLINSON 